\title{
ACHADO ACIDENTAL DE AGENESIA RENAL UNILATERAL EM UM PAPAGAIO-DE-PEITO-ROXO (Amazona vinacea) EM EXAME NECROSCÓPICO - RELATO DE CASO
}

\author{
(Accidental findings of unilateral renal agenesia in a vinaceous-breasted parrot (Amazona vinacea) in \\ necroscopic examination - case report)
${ }^{1}$ Maraya Lincoln Silva, ${ }^{2}$ Matheus Alves Moreira, ${ }^{2}$ Gustavo Bauer Costa da Silva, ${ }^{2}$ Adriano Bauer Costa da Silva
${ }^{1}$ Universidade Estadual Paulista Júlio de Mesquita Filho (UNESP), Campus de Jaboticabal, São Paulo, Brasil. ${ }^{2}$ Clínica Veterinária Amazoo Pets de Jundiaí, São Paulo, Brasil.

\section{*Correspondência: marayals@yahoo.com.br}

RESUMO: O sistema renal das aves é composto por um par de rins que estão localizados dentro da cavidade formada pela face ventral do sinsacro. Os rins estendem-se da borda caudal dos pulmões até o sinsacro caudal e, na maioria das aves, é composto por três divisões: cranial, média e caudal. Compreendem 1 a 2,6\% do peso corporal comparado a uma média de 0,5\% de peso corporal em mamíferos. Uma característica única do rim das aves é a presença de dois tipos de néfrons, com e sem alça de Henle. A alça de Henle permite a concentração da urina e é a razão principal pela qual as aves e os mamíferos são as únicas classes de vertebrados capazes de produzir urina hiperosmótica. Entretanto, a maioria dos néfrons das aves não possui alça de Henle e encontram-se dentro do córtex sendo a concentração da urina limitada (ECHOLS, 2006). A aplasia ou agenesia renal é caracterizada por uma falha no desenvolvimento renal de forma que não exista tecido renal reconhecível, podendo ser unilateral ou bilateral. A agenesia unilateral do rim é compatível com a vida e o animal pode viver sem grandes problemas contanto que o outro rim seja normal. Sendo assim, esta pode permanecer despercebida durante a vida e ser reconhecida apenas no momento de necropsia (NEWMAN, 2013). Durante o procedimento necroscópico de um papagaio-do-peito-roxo, fêmea, notou-se ausência de estrutura renal do lado direito, o qual era compreendido apenas por uma cápsula. Foi observado discreto aumento do rim esquerdo, caracterizando hipertrofia de rim contralateral, provocado por mecanismos compensatórios, devido à ausência de um rim. Constatou-se agenesia renal, cujo diagnóstico foi ocasional no momento da necropsia, e não afetava nenhuma condição fisiológica do animal em vida.

Palavras-chave: aplasia; aves; necropsia; rim.

\section{Referências}

ECHOLS, M, S. Evaluating and Treating the Kidneys. In: HARRISON, G.J.; LIGHTFOOT, T.L. Clinical Avian Medicine. Florida, Vol.2, Sphinx Publishing, cap 16, p. 451-492, 2006.

NEWMAN, S. J. O Sistema Urinário. In: MCGAVIN, M.D.; ZACHARY, J.F. Bases da Patologia em Veterinária. 5a ed, Editora Elsevier, cap 11, p. 592-662, 2013. 